\title{
RESILIENSI ANAK PASCA BENCANA: LITERATUR REVIEW
}

\author{
Susanti Niman ${ }^{1,2}$, Mustika Sari ${ }^{2}$ \\ ${ }^{1}$ Program studi Sarjana Keperawatan STIKes Santo Borromeus, Indonesia \\ ${ }^{2}$ Fakultas Ilmu Keperawatan, Universitas Indonesia, Indonesia \\ Coresponding Author: Susanti Niman. Bachelor of Nursing Programme, STIKes Santo Borromeus, \\ Bandung Barat, West Java. Email: susantiniman@gmail.com.
}

\begin{abstract}
Abstrak
Latar Belakang: Bencana mengancam kehidupan jutaan anak. Anak merupakan kelompok usia terbesar yang mengalami bencana di seluruh dunia. Diperkirakan ada lebih dari 100 juta anak terpapar bencana setiap tahun. Anak termasuk dalam kelompok beresiko yang paling rentan. Dampak bencana pada kelompok usia anak lebih mengkhawatirkan dibanding usia dewasa. Anak lebih beresiko mengalami trauma akibat bencana. Resiko tersebut tergantung pada tingkat perkembangan kognitif dan emosi. Resiliensi dibutuhkan untuk proses recovery survivor bencana. Resiliensi yang dimiliki oleh individu akan menurunkan tingkat PTSD. Penelitian ini bertujuan untuk meninjau secara sistematis faktor-faktor yang mempengaruhi resiliensi anak setelah bencana. Subjek dan Metode: Literatur review dibuat berdasarkan metode kuantitatif dengan model PRISMA. Variabel dependen adalah resiliensi anak. Variabel independen adalah ikatan positif pengasuh utama, regulasi emosi, fleksibilitas kognitif, persepsi, kontrol dan dukungan sosial. Dari 31 artikel, 5 artikel yang memenuhi kriteria inklusi dan eksklusi yang dipilih untuk penelitian ini. Artikel-artikel tersebut dikumpulkan dari 3 sumber basis data meliputi EBSCOhost, Science Direct dan Pubmed. Hasil: faktor-faktor psikososial kunci yang terkait dengan resiliensi. Faktor psikososial kunci tersebut termasuk pentingnya ikatan positif dengan pengasuh utama selama perkembangan, regulasi emosi, fleksibilitas kognitif, persepsi dan kontrol serta ketersediaan dukungan sosial untuk resiliensi di sepanjang rentang usia. Kesimpulan: Resiliensi pada anak dipengaruhi oleh faktor psikososial. Resiliensi membantu kesiapan menghadapi bencana dan meminimalkan dampaknya.
\end{abstract}

Kata kunci: resiliensi anak, bencana

Abstract

Background: Disasters threaten the lives of millions of children. Children are the largest age group that has experienced disasters throughout the world. It is estimated that there are more than 100 million children exposed to disasters every year. Children are included in the most vulnerable risk groups. The impact of disasters on the age group of children is more worrying than the age of adulthood. Children are more at risk of experiencing trauma due to disasters. The risk depends on the level of cognitive and emotional development. Resilience is needed for the process of disaster survivor recovery. The Resilience that is owned by individuals will reduce the level of PTSD. This study aims to systematically review the factors that influence the resilience of children after a disaster. Subjects and Methods: A systematic review was made based on quantitative methods with the PRISMA model. The dependent variable is child resilience. The independent variable is positive parenting of the primary caregiver, emotional regulation, cognitive flexibility, perception, control, and social support. Of the 31 articles, 5 articles that met the inclusion and exclusion criteria were selected for this study. The articles were collected from 3 database sources including EBSCOhost, Science Direct and Pubmed. Results: Key psychosocial factors associated with resilience. These key psychosocial factors include the importance of positive bonds with primary caregivers during 
development, emotional regulation, cognitive flexibility, perception and control and the availability of social support for resilience throughout the age range.

Conclusion: Resilience in children is influenced by psychosocial factors. Resilience helps disaster preparedness and minimizes its impact

Keywords: children resilience, disaster

\section{PENDAHULUAN}

Bencana mengancam kehidupan jutaan anak di dunia, khususnya negara - negara dengan pendapatan rendah dan sedang (Martin, 2010; Mudavanhu et al, 2015). Terdapat 66 juta anak terdampak oleh bencana (Mudavanhu et al,2015). Anak merupakan kelompok usia terbesar yang mengalami bencana di seluruh dunia. Diperkirakan ada lebih dari 100 juta anak terpapar bencana setiap tahun. Di Amerika terdapat $14 \%$ anak mengalami bencana. Bencana yang anak dapat mengancam kesehatan jiwa anak (Lai, Lewis, Livings, Greca \& Esnard, 2017). Bencana juga dapat berdampak pada perkembangan psikologis dan kepribadiaan anak (Feitelberg, 2007). Dampak bencana pada kelompok usia anak lebih mengkhawatirkan dibanding usia dewasa. Anak termasuk dalam kelompok beresiko yang paling rentan (Pahleviannur, 2019). Anak lebih beresiko mengalami trauma akibat bencana. Resiko tersebut tergantung pada tingkat perkembangan kognitif dan emosi (Raccanelo, Burro \& Hall, 2017).

Reaksi psikologis yang dialami anak pasca bencana adalah ansietas, depresi, phobia dan post traumatic stress disorder (Raccanelo, Burro \& Hall, 2017). Posttraumatic stress disorder (PTSD) merupakan gejala psikologis yang sering dialami oleh anak dan remaja survivor gempa bumi. Terdapat sekitar $4.5 \%$ 95\% anak dan remaja survivor gempa bumi menunjukkan gejala PTSD (Zhang, Y., Zhang, J., Zhu, S., Du, C., \& Zhang, W, 2017). Gejala pascatrauma yang dialami pada korban bencana adalah adanya pikiran dan perasaan negatif, perilaku avoidance dan hyperarousal (Chen \& Wu, 2017). Gejala PTSD pada remaja bisa berkisar dari rasa takut, mimpi buruk, gangguan pikiran, marah dan agresi
(Dithal Shibanuma, Miyaguchi, Kiriya \& Jimba, 2019). Gejala psikologis lain yang muncul pada anak pasca bencana tergantung pada usia dan jenis kelamin. Anak usia pra sekolah lebih sering menunjukkan gejala perilaku antisosial dan agresif dibandingkan dengan anak kelompok usia yang lebih tua. Anak laki - laki lebih memperlihatkan gejala perilaku seperti agresif. Anak perempuan lebih memperlihatkan gejala perilaku depresi (Raccanelo, Burro \& Hall, 2017).

Individu dapat merespons kejadian traumatik dengan cara yang sehat dan melupakan pengalaman traumatik. Namun ada sebagian individu lainnya bereaksi dengan pengalaman traumatik secara tidak disadari dengan cara memisahkan memori atau emosi yang tidak menyenangkan dari kesadaran utama. Mekanisme pertahanan diri tersebut dikenal dengan istilah disosiasi. Disosiasi pada anak muncul karena anak tidak dapat menghadapi kondisi trauma dengan mudah (Alayarian, 2019).

'Disosiasi sehat' adalah mekanisme pertahanan yang efektif digunakan untuk pengalihan perhatian secara sadar dari rasa sakit, menghalau pengalaman traumatis dari kesadaran yang dapat membanjiri struktur dan fungsi psikis sehingga memungkinkan individu untuk memproses dan mencerna kejadian dalam 'ruang psikis' yang aman (Alayarian, 2019).

Kondisi psikologis yang dialami merupakan bagian yang alami dan tergantung pada konteks sosial. Prilaku kesiapsiagaan individu berkaitan dengan presepsi tentang resiko yang dirasakan terkait keparahan, kerentanan pribadi, kemampuan untuk mempersiapkan (efikasi) dan perilaku spesifik yang mungkin dilakukan untuk mengurangi resiko. Sehingga 
masalah kesehatan jiwa seperti posttraumatik stress, ansietas, depresi dan gejala somatik yang ditemukan pasca trauma dipengaruhi oleh disaster preparedness (Welton-Mitchell; James; Khanal \& James, 2018)

Anak-anak yang mengalami bencana alam rentan terhadap risiko berkembangnya masalah kesehatan mental di masa yang akan datang akibat pengaruh dari trauma. Masalah kesehatan mental terjadi pada anak-anak yang tinggal di negara maju setelah bencana alam menunjukkan proporsi epidemi masalah kesehatan jiwa yanng dapat bertahan dalam periode waktu lama serta berpotensi menyebabkan disabilitas seumur hidup (Schwind et all, 2018).

Hanya sekitar 20-30\% anak dan remaja yang teridentifikasi dan mendapatkan pelayanan kesehatan jiwa. Berdasarkan hal tersebut, intervensi yang bersifat prevensi harus diberikan di masyarakat untuk meningkatkan faktor protektif, mengurangi prevalensi dan beban yang disebabkan oleh masalah psikologis (Bennett et al, 2015).

Kemampuan untuk mengadopsi strategi koping yang berhasil dalam menghadapi kesulitan yang berat akan menentukan resiliensi psikologis. Resiliensi dalam mengatasi bencana merupakan kemampuan mengatasi stres dengan sukses. Resiliensi dibutuhkan untuk proses recovery survivor bencana. Resiliensi yang dimiliki oleh individu akan menurunkan tingkat PTSD (Shepherd, Mcbride \& Lovelock, 2017).

Resiliensi secara luas didefinisikan sebagai kemampuan dinamis untuk beradaptasi dengan berhasil dalam menghadapi kesulitan, trauma, atau ancaman yang signifikan. Resiliensi itu rumit dan dapat dikonseptualisasikan secara menyeluruh dengan potensi untuk berubah sepanjang masa hidup seorang individu. Beberapa studi awal kunci tentang resiliensi dilakukan pada tahun 1970-an pada anak-anak berisiko untuk psikopatologi yang berasal dari beragam faktor risiko, termasuk penyakit mental serius orang tua atau dibesarkan di panti asuhan, dan juga dalam subkelompok yang teridentifikasi dari anak-anak tersebut yang menunjukkan perkembangan normatif. Berbagai studi selanjutnya pada anak-anak dan kemudian pada orang dewasa ditemukan faktor-faktor psikososial kunci yang terkait dengan resiliensi. Faktor psikososial kunci tersebut termasuk pentingnya ikatan positif dengan pengasuh utama selama perkembangan, regulasi emosi, fleksibilitas kognitif, persepsi dan kontrol serta ketersediaan dukungan sosial untuk resiliensi di sepanjang rentang usia (Horn \& Feder, 2018)

Resiliensi adalah suatu konsep rumit yang melibatkan suatu proses aktif yang menghasilkan adaptasi positif dalam menghadapi kesulitan besar dan kemampuan untuk menjaga kesehatan mental atau bangkit kembali meskipun kondisi sulit. Resiliensi seperti karakteristik dan kepribadian, terkadang dianggap sebagai faktor sifat atau predisposisi yang dapat dikembangkan sebagai bagian dari proses menguasai keterampilan yang relevan dalam konteks lingkungan. Resiliensi merupakan faktor protektif untuk mempertahankan kesehatan jiwa atau mengatasi masalah kesehatan jiwa akibat bencana. Kesadaran akan kesehatan jiwa yang difasilitasi pada anak dan remaja dapat meningkatkan kesadaran diri dan resiliensi (Okuyama, Funakoshi, Tomita, Yamaguchi \& Matsuoka, 2018).

\section{METODE}

Sebagaimana diuraikan oleh Moher et al. (2018) menguji secara kritis, mengevaluasi, dan mensintesis literatur tentang reliensi dan faktor yang berhubungan dengan resilensi dari tinjauan sistematis. Untuk tujuan ini, langkahlangkah berikut telah dilakukan, yaitu: a) perumusan ruang lingkup tinjauan dan pertanyaan penelitian, b) pencarian literatur menyeluruh, c) ekstraksi data rinci, dan d) integrasi temuan utama dan implikasi. Meta analisis tidak dilakukan karena heterogenitas 
lintas studi dalam hal karakteristik sampel (mis., berbagai tahap perawatan) dan hasil yang diukur.

\section{Kriteria Pencarian dan Inklusi Literatur}

Pencarian secara sistematis pada database elektronik berikut ini yang diterbitkan sejak tahun 2014 dan 2019 dilakukan pada database EBSCOhost dan Science Direct . Kata kunci yang dicari menggunakan kata kunci yang dipilih yaitu: 'disaster', $P T S D$ ', dan'earthquake' dan 'Children Resilience'. Studi yang dipilih untuk kriteria inklusi memeriksa aspek resiliensi anak dengan PTSD termasuk: (a) penilaian subyektif (kualitatif) atau obyektif, perubahan sejak bencana (data longitudinal); atau (b) skor terstandarisasi, atau perbandingan dengan norma atau kelompok kontrol. Studi yang diterbitkan dalam bahasa selain Inggris dan non-empiris (yaitu, ulasan, laporan kasus, buku, ulasan buku, komentar, pedoman praktik, abstrak konferensi, dan disertasi) dikecualikan. Artikel full text. Daftar referensi dari makalah yang dipilih juga ditinjau untuk memastikan dimasukkannya semua makalah yang relevan.

\section{HASIL}

Berdasarkan karakteristik Studi yang dilakukan review semua studi yang ditinjau adalah kuantitatif, dengan sebagian besar studi menggunakan studi longitudinal (66.6\%). Ukuran sampel bervariasi dari 195 hingga 757 anak dan remaja. Berbagai waktu penelitian sejak terjadinya bencana dimasukkan dalam studi, yaitu bencana terjadi setelah 8 bulan hingga 20 bulan.

\section{PEMBAHASAN}

Tinjauan literatur ini memberikan bukti umum tentang resiliensi anak setelah bencana; Namun, dibutuhkan lebih banyak data untuk memahami fenomena ini. Untuk meningkatkan penelitian ini, kegiatan selanjutnya harus berbasis teori, mencocokkan indikator pengukuran, dan menggunakan metode statistik yang sesuai, sehingga dapat memberikan gambaran yang lebih jelas bagaimana resiliensi pada anak.
Kemampuan peneliti untuk menarik kesimpulan tentang resiliensi anak yang menghadapi bencana juga terhambat oleh kurangnya penelitian yang menggunakan kerangka kerja ini sebagai dasar untuk pendekatan penelitian.

Keterbatasan

Selain masalah yang disebutkan di atas, karakteristik tertentu dari basis penelitian membuatnya sangat sulit untuk menarik kesimpulan yang kuat. variasi dari studi kuantitatif dengan berbagai desain, beberapa menggunakan kelompok kontrol dan tanpa kelompok kontrol. Selain itu, hampir semua penelitian mengandalkan laporan tentang kemunculan PTSD dengan tanda-tanda depresi meskipun ada kelemahan yang diketahui terkait dengan metode ini.

Implikasi untuk Praktek Klinis

Terlepas dari kesenjangan dalam literatur saat ini, dengan mengadopsi kerangka kerja resiliensi anak, ada beberapa implikasi untuk praktik klinis. Pertama, studi harus fokus pada dampak bencana yang dapat mempengaruhi stabilitas psikososial harus secara rutin dinilai dalam populasi ini. Kedua, perawat ketika bersama dengan anak harus peka terhadap kemungkinan perbedaan budaya, harus mempertimbangkan anak dalam konteks sosial-ekologis yang lebih besar, dan memperhatikan subkelompok yang mungkin berisiko tinggi (misalnya, anak dengan disabilitas). Akhirnya, berdasarkan review kami, dukungan psikososial pada anak sebelum mengalami bencana perlu dilakukan terus menerus dan dijadwalkan sehingga anak akan bebas dari dampak psikososial yang mungkin timbul, yaitu depresi dan PTSD pasca bencana.

\section{SIMPULAN}

Ada bukti resiliensi anak dapat menurunkan resiko PTSD pasca bencana. Keterbatasan dalam literatur saat ini menghambat 
kesimpulan mengenai dampak resiliensi building programme pada resiliensi anak. Penelitian lebih lanjut yang dilakukan dari perspektif teori resiliensi anak diperlukan untuk menutup kesenjangan dalam literatur,

\section{DAFTAR PUSTAKA}

Alayarian, A (2019). Trauma, resilience and healthy and unhealthy forms of dissociation. Journal of Analytical Psychology, 2019, 64, 4, 587-606

Bennett, K., Manassis, K., Duda, S., Bagnell, A., Bernstein, G. A., Garland, E. J., ... Wilansky, P. (2015). PREVENTING CHILD and ADOLESCENT ANXIETY DISORDERS: OVERVIEW of SYSTEMATIC REVIEWS. Depression and Anxiety, 32(12), 909-918. https://doi.org/10.1002/da.22400

Bakker, L. P; Smastuen, M. C; Reichelt, J. G; Gjerstad,C. L; Tonnessen, A; Wetsaeth, L; Herlofsen, P. H; Grov, E.K (2019). The trajectory of symptom burden in exposed and unexposed survivors of a major avalanche disaster : a 30 year long-term follow-up study. BMC Psychiatry 19:175.

Chen, J., \& Wu, X. (2017). Posttraumatic Stress Symptoms and Posttraumatic Growth in Children and Adolescents Following an Earthquake: A Latent Transition Analysis. Journal of Traumatic Stress, 30(6), 583-592. https://doi.org/10.1002/jts.22238

Horn, S. R., \& Feder, A. (2018, May 1). Understanding Resilience and Preventing and Treating PTSD. Harvard Review of Psychiatry, Vol. 26, pp. 158-174. https://doi.org/10.1097/HRP.0000000000 000194 memperbaiki model resiliensi, dan memberikan panduan yang jelas untuk mengintegrasikan data ini ke dalam praktik klinis.

Kitchener, Betty A; Jorm, Anthony F. (2008). Early Intervention in the Real World: Mental Health First Aid: An Internasional Programme for early intervention. Early Intervention in Psychiatry, 55-61.

Manzoor, S., \& Ali, M. (2018). Disaster and mental health: A need for multipronged approach. In Indian Journal of Health and Well-being (Vol. 2018). Retrieved from http://www.iahrw.eom/index.php/home/j oumal_detail/19\#list

Mohammadinia, L; Zavareh, D.K ; Ebadi, A; Malekafzali, H; Ardalan, A; Fazel,M (2018). Characteristics and components of children's and adolescents' resilience in disasters in Iran : a qualitative study. International Journal of qualitative studies on health and well-being vol 13

Moher, D., Liberati, A., Tetzlaff, J., Altman, D. G., Group, P., \& The, P. G. (2009). Preferred reporting items for systematic reviews and meta-analyses: the PRISMA statement. PLoS medicine, 6(7), e1000097. doi:http://10.1371/journal.pmed.10000 97

Okuyama, J., Funakoshi, S., Tomita, H., Yamaguchi, T., \& Matsuoka, H. (2018). Longitudinal characteristics of resilience among adolescents: A high school student cohort study to assess the psychological impact of the Great East Japan Earthquake. Psychiatry and 
Clinical Neurosciences, 72(11), 821-835. https://doi.org/10.1111/pcn.12772

Shepherd, D., McBride, D., \& Lovelock, K. (2017). First responder well-being following the 2011 Canterbury earthquake. Disaster Prevention and Management, 26(3), 286-297. https://doi.org/10.1108/DPM-06-20160112

Welton-Mitchell, C., James, L. E., Khanal, S. N., \& James, A. S. (2018). An integrated approach to mental health and disaster preparedness: A cluster comparison with earthquake affected communities in Nepal 11 Medical and Health Sciences
1117 Public Health and Health Services 17 Psychology and Cognitive Sciences 1701 Psychology. BMC Psychiatry, 18(1). https://doi.org/10.1186/s12888018-1863-z

Zhang, Y., Zhang, J., Zhu, S., Du, C., \& Zhang, W. (2017). Prevalence of probable posttraumatic stress disorder and determination of its relationship with everyday functioning in children and adolescents by using generalized estimating equations. Asia-Pacific Psychiatry, 9(2). https://doi.org/10.1111/appy.12262 